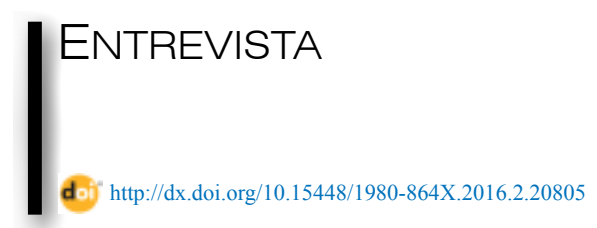

\title{
Corporativismo e Salazarismo em perspectiva: o olhar de Fernando Rosas
}

\author{
Corporatism and Salazarism in perspective: \\ the view of Fernando Rosas \\ Corporativismo y Salazarismo en perspectiva: \\ la mirada de Fernando Rosas
}

Luciano Aronne de Abreu*
Paula Borges Santos**

Atualmente, registra-se a retomada de estudos sobre os corporativismos históricos do período de Entre Guerras. Por um lado, assiste-se à produção de novos estudos sobre dimensões econômicas, sociais e políticas daqueles projetos. Discute-se ainda a persistência e a atualização de algumas das suas formas de organização econômica e social, nas sociedades contemporâneas. Por outro lado, promove-se a revisão de literatura, designadamente através de interpretações que recusam a identificação entre fenômenos como o fascismo ou o nacionalismo e um instrumento político e administrativo estatal, destinado a disciplinar os interesses econômicos e sociais, como foi o corporativismo. O momento justifica, portanto, uma breve conversa com Fernando Rosas (Lisboa, 18-04-1946), eminente acadêmico português a quem a historiografia portuguesa deve o maior impulso alguma vez dado ao estudo do Estado Novo.

\footnotetext{
* Professor do Programa de Pós-graduação em História da Pontifícia Universidade Católica do Rio Grande do Sul (PUCRS). <luciano.abreu@pucrs.br> <dados biográficos/biographic data>

**Investigadora do Instituto de História Contemporânea da Universidade Nova de Lisboa (IHC/UNL). < paula.borges.santos@fcsh.unl.pt> < dados biográficos/biographic data>
} 
Professor catedrático emérito do departamento de História da Faculdade de Ciência Sociais e Humanas da Universidade Nova de Lisboa e Investigador Integrado do Instituto de História Contemporânea da mesma instituição, do qual foi fundador e Presidente da Direção entre 1994 e fevereiro de 2013. Entre 2013 e 2016, foi também coordenador do Grupo de Investigação História Política Comparada. Publicou variadíssimas obras como autor, dirigiu, coordenou e é coautor de muitas outras na área da sua especialidade (história portuguesa e europeia do século XX) ${ }^{1}$. Foi ainda deputado da Assembleia da República em 2000 e 2001 e de 2005 a 2010.

Ao longo de sua vasta obra, Fernando Rosas rompeu com preconceitos sobre o tratamento da contemporaneidade e, em anos de recente consolidação da democracia portuguesa, tratou amplamente a ditadura de Salazar e Caetano, nas suas várias vertentes, e formou várias gerações de investigadores, que continuaram a cultivar a investigação científica sobre aquele regime. O estudo das questões econômicas foi uma das suas áreas de trabalho. Nessa medida, privilegiando uma leitura marxista da realidade histórica, construiu uma interpretação própria da experiência histórica do corporativismo português, das suas funcionalidades políticas, que entendeu estarem centradas na recomposição das classes dominantes e na reconstrução do Estado, que fez escola. Registrar a sua posição e conhecer o seu posicionamento sobre a mais recente dinâmica dos estudos sobre corporativismo, são os objetivos principais desta entrevista que a seguir publicamos.

$$
* * *
$$

\footnotetext{
${ }^{1}$ Entre elas: As primeiras eleições legislativas sob o Estado Novo: as eleições de 16 de Dezembro de 1934 (O Jornal, 1985); O Estado Novo nos Anos 30. Elementos para o Estudo da Natureza Económica e Social do Salazarismo (1928-1938) (Estampa, 1986); O salazarismo e a Aliança Luso-Britânica: estudos sobre a política externa do Estado Novo nos anos 30 a 40 (Fragmentos, 1988); Salazar e o Salazarismo (coord.) (Publ. D. Quixote, 1989); Portugal Entre a Paz e a Guerra (1939/45) (Estampa, 1990); Portugal e o Estado Novo (1930/60) (coord.) (Presença, 1993); Dicionário de História do Estado Novo (coord.) (Círculo de Leitores, 1996); Salazarismo e o Fomento Económico (Editorial Notícias, 2000); Portugal século XX: 1890-1976: pensamento e aç̧ão política (Editorial Notícias, 2004); Lisboa Revolucionária (1908-1975) (Tinta da China, 2010); Corporativismo, Fascismos, Estado Novo (coord.) (Almedina, 2012); Salazar e o Poder. A Arte de Saber Durar (Tinta da China, 2012, $1^{\text {a }}$ edição e 2013, $2^{\mathrm{a}}$ edição); Estado Novo e Universidade. A Perseguição aos Professores (coord.) (Tinta da China, 2013).
} 
- Pode-se definir o Estado Novo português, de fato, como um regime de tipo corporativista? Em que medida?

- Aplicando a conhecida distinção de Renzo de Felice (fascismo enquanto movimento ou enquanto regime) ao estudo dos corporativismos e tendo presente a distância que existiu em todas as suas experiências históricas entre o nível ideológico-retórico da narrativa doutrinária do fenômeno e a realidade da sua aplicação políticoadministrativa, econômica e social, penso que o Estado Novo português se pode considerar, indiscutivelmente, como um regime corporativo. Doutrinariamente assim o apresentou Salazar nos seus discursos fundadores do novo regime; institucionalmente o consagrou a Constituição de 1933, e na sua continuada aplicação prática entre 1933 e 1947 ao controle repressivo do fator trabalho, à regulação geral da economia e ao enquadramento ideológico do mundo laboral, bem se pode falar de um corporativismo de Estado, de predominância econômica e de clara apetência totalizante.

- Pode-se dizer que o modelo corporativista se constituiu num projeto definido claramente pelo Salazarismo, ou este teria sido a resultante das múltiplas influências e acordos do regime com seus diferentes apoiadores?

- O Estado Novo salazarista proclamava-se claramente como corporativo. Mas produto que foi, como todos os regimes fascistas seus contemporâneos, de uma coligação das várias direitas da direita portuguesa, o corporativismo salazarista teve que fazer algumas cedências, sobretudo no funcionamento do sistema político, ao peso que as concessões liberal-conservadoras ainda detinham na gênese do novo regime e no momento do acesso de Salazar à chefia do governo. Nesse sentido, as direitas salazaristas e nacional-corporativas tiveram de aceitar uma Assembleia Nacional e um Presidente da República formalmente eleitos pelo sufrágio direto dos cidadãos (ainda que, no primeiro caso, a partir de uma lista nacional única proposta pelo partido igualmente único). $\mathrm{O}$ rápido esvaziamento dos poderes efetivos dos dois órgãos pela prática governativa (uma ditadura de chefe do Governo), por um lado, e o efetivo poder ganho pela organização corporativa e para-corporativa no controle do mundo laboral e na regulação da economia sob tutela do Estado, por outro, permitem falar do corporativismo salazarista como um fator central no "saber durar" salazarista. 
- A que se pode atribuir a longa duração do regime de Salazar e Caetano? Quais teriam sido suas principais mudanças e recorrências entre 1933 e 1974, especialmente em relação à questão do corporativismo?

- Para responder a essa questão escrevi recentemente um livro $^{2}$ onde procuro analisar o que considero serem os principais fatores da longa durabilidade do regime, daquilo que chamo "a arte de saber durar" do salazarismo ${ }^{3}$. Um deles, precisamente o mais estavelmente constante e durável, é a organização corporativa. O corporativismo salazarista foi instrumento político e administrativo para o Estado Novo ir realizando, com altos e baixos, entre períodos de tensão agudos e outros de maior consenso, um triplo objetivo estratégico: conter, desarticular e reprimir as tentativas reivindicativas do trabalho assalariado, garantido policialmente o seu baixo custo nominal e real; regular, em nome de um "interesse nacional" de que o regime era o único e unilateral intérprete, as contradições de interesses entre os setores dominantes da oligarquia econômica e social (industrialistas versus agraristas, produção nacional versus comércio colonial, de um lado, e comércio internacional do outro), e ainda a relativa sobrevivência de importantes setores pequenos e médios da produção e serviços, vegetando à sombra de baixíssimos salários e da multímoda proteção do Estado. A ação dos organismos setoriais de regulação econômica (ditos "para-corporativos" e realmente estatais), da cartelização corporativa, do condicionamento industrial, da pauta umbrosa, da vigilância policial e as generosas taxas de lucro e acumulação que proporcionaram foram construindo esse consenso sempre tenso, mas duradouro, das classes dominantes e de parte dos setores empresariais intermédios em torno do regime que só os efeitos conjugados da guerra colonial e da crise petrolífera do início dos anos 70 viriam a abalar seriamente.

- Sob o pondo de vista dos interesses portugueses - políticos, econômicos e culturais - qual sua avaliação das relações entre os Estados Novos português e brasileiro?

- É certo que o Estado Novo salazarista poderá ter sentido simpatia pela viragem que o golpe de novembro de 1937, instituindo o Estado Novo brasileiro e a ditadura de Getúlio Vargas, trouxera para o Brasil,

${ }^{2}$ ROSAS, Fernando. Salazar e o Poder. A Arte de Saber Durar. Lisboa: Tinta da China, 2012 ( $1^{\mathrm{a}}$ edição) e 2013 ( $2^{\mathrm{a}}$ edição).

${ }^{3} \mathrm{Na}$ obra consideram-se 5 fatores principais: a gestão da violência, o controlo das Forças Armadas, a cumplicidade da Igreja Católica, a organização corporativa e a apetência totalitária do regime. 
até pela retórica nacional corporativista que o acompanhou. Seguro é também que, no início da II Guerra Mundial, Salazar alimentara o desenho estratégico de uma "zona de paz e ordem" latina, cristã, autoritária, que funcionasse como área transatlântica de neutralidade face aos beligerantes, agrupando a Argentina, o Brasil de Vargas, o Portugal de Salazar, a Espanha franquista e a Itália de Mussolini, uma espécie de grande reserva de segurança e durabilidade desses regimes durante e após o conflito, a que haveriam de ficar imunes. É claro que o alinhamento do Brasil de Vargas na aliança pancontinental com os EUA contra o nazi-fascismo, em 1942, constituiu uma dura desilusão para o ditador português. Que se tornou em claro esfriamento de relações, em 1943, face aos rumores de que Vargas, no encontro com Roosevelt, em Natal, em Janeiro desse ano, teria mostrado abertura ao pedido norte-americano de participação de tropas brasileiras num eventual (e unilateral) desembarque dos aliados nos Açores. De resto, além de uma visita de António Ferro ao Brasil em 1941 (de que terá resultado um vago programa de intercâmbio cultural e artístico sem consequências de nota), não parece poder falar-se, neste período, de um real estreitamento de relações, nem por via de alguma identificação ideológica.

- Após o 25 de Abril, que tipo de heranças ou recorrências do Salazarismo e do seu modelo corporativo podem ser ainda hoje observadas em Portugal?

- Alguns autores portugueses, com destaque para os trabalhos de Manuel Lucena, quiseram ver na continuidade de vários organismos de coordenação econômica setorial ou intersetorial para o período posterior ao 25 de Abril e durante alguns anos, a evidência de elementos essenciais de continuidade no domínio econômico do corporativismo. Não vejo isso assim. A revolução portuguesa de 1974/75, ou seja, a vasta movimentação popular revolucionária que ela despertou liquidou política, ideológica e institucionalmente a organização corporativa, alterou a natureza do Estado que a suportava e os interesses de classe que lhe subjaziam. Não se limitou a dissolver os Grémios, Sindicatos Nacionais, as Casas do Povo, as Casas de Pescadores e as Corporações (substituindo-as por novas lógicas de representação social). Igualmente ocupou empresas abandonadas, tentou a autogestão pelos trabalhadores, fez a Reforma agrária, impôs nacionalizações, organizou o controle operário. Ou seja, alterou profundamente as relações até aí existentes entre o capital e o trabalho. $\mathrm{O}$ corporativismo era um instrumento de dominação social e política da ditadura estadonovista que desapareceu 
com ela. É certo que permaneceram (sobretudo até à adesão à CEE) algumas instituições de regulação econômica formalmente herdadas dos antigos organismos de coordenação econômica. Mas não só esses eram os organismos menos corporativos do corporativismo, como a lógica interventiva que lhes passou a presidir pouco ou nada tinha a ver com as estratégias regulatórias que o anterior regime lhes imprimira.

Bem sei que se tenta hoje, sobretudo no domínio de alguma ciência política ou sociologia política, fazer renascer das cinzas dos velhos regimes fascistas ou afins uma espécie de neocorporativismo sem mácula. Mas, salvo o devido respeito, essa é uma operação mais do domínio da ideologia do que da comparação historiográfica.

- Em sua opinião, pode-se dizer que há, nos últimos anos, uma retomada e renovação dos estudos sobre o corporativismo? Em que medida eles inovam ou reafirmam os estudos mais clássicos sobre a temática?

- Em Portugal essa renovação historiográfica existe e eu separo-a claramente da tal dimensão neocorporativa que reputo de escassa densidade e interesse para o estudo histórico do fenômeno. Mas é um movimento ainda limitado. $\mathrm{O}$ seu grande contributo (vide os estudos pioneiros de Álvaro Garrido) é passar do conhecimento geral da doutrina e da legislação para a investigação em concreto: a) dos mecanismos e das lógicas de funcionamento dos organismos corporativos nos principais setores econômico-sociais que enquadravam e regulavam aos diversos níveis (produção, transformação, comercialização); b) das elites que os dirigiam, das suas contradições e relações com o poder político; c) das estruturas de dominação e controle social. É esse salto inovador para a prática econômica, social e política do corporativismo enquanto regime em concreto que é preciso dar, superando um certo enquistamento metafísico no seu estudo enquanto discurso meramente teórico.

- Quais seriam os principais pontos de convergência e divergência entre o corporativismo histórico e o que hoje tem sido chamado de neocorporativismo?

- Como considero o corporativismo um fenômeno histórico e uma categoria conceitual só historicamente entendível no contexto que historicamente o produziu - aquele em que emergem os regimes fascistas ou do tipo fascista - não me identifico com as abordagens que deshistoricizam o estudo do corporativismo e que, de alguma forma, o 
reinventam como uma técnica de regulação social, (Álvaro Garrido), reduzindo-o a uma "taxonomia das políticas de regulação social", aparentemente despida de ideologia e de antecedentes. Por isso mesmo me parece tão discutível a recuperação do corporativismo como um "neo-corporativismo", de "associação", "contratual", feito equivalente da contratação social corrente das sociedades capitalistas de regime democrático-parlamentar. Historicamente, politicamente, há entre eles diferenças essenciais. O corporativismo, enquanto regime, foi uma tentativa de "solucionar", ou seja, de eliminar pela força a conflitualidade social, de sujeitar o trabalho ao capital. Tinha um invólucro doutrinário, uma concessão organicista e totalizante da sociedade em que a luta de classes surgia como um comportamento anômalo e desviante relativamente à "ordem natural das coisas", ordem que o Estado haveria de receber, extirpando essas patologias subversoras.

É nesse preciso sentido que se pode dizer que não há corporativismos democráticos. O que há nas democracias é contratualização, ou seja, negociação entre sujeitos distintos e conflitantes, no quadro de um confronto que se aceita como inevitável e normal e encontra, com mais ou menos dificuldade, os seus pontos de equilíbrio. Neste caso, ao contrário do corporativismo, não se trata de uma harmonia essencialista entre o capital e o trabalho imposta pela ordem imanente de um qualquer ente orgânico.

\section{Autores/Authors:}

LUCIANO ARONNE DE ABREU <luciano.abreu@pucrs.br>

- Professor do Programa de Pós-graduação em História da Pontifícia Universidade Católica do Rio Grande do Sul (PUCRS). Doutor em Estudos Históricos Latino Americanos pela Universidade do Vale do Rio dos Sinos (Unisinos). Tem experiência na área de História, com ênfase em História do Brasil República, atuando principalmente nos seguintes temas: História do Rio Grande do Sul, Era Vargas e Autoritarismo. É autor dos livros Getúlio Vargas: a construção do mito (EdiPUCRS, 1997) e Um Olhar Regional sobre o Estado Novo (EdiPUCRS, 2007).

- Adjunct Professor at Pontifícia Universidade Católica do Rio Grande do Sul (PUCRS), Ph.D. in Latin-american Studies from the Universidade do Vale do Rio dos Sinos (Unisinos). Has experience in History, focusing on History of Brazilian Republic, and researching the following subjects: Rio Grande do Sul, Vargas' New State, and Authoritarianism. He is the author of Getúlio Vargas: a construção do mito (EdiPUCRS, 1997) and Um Olhar Regional sobre o Estado Novo (EdiPUCRS, 2007).

PAUla BORGES SANTOS <paula.borges.santos@fcsh.unl.pt>

- Investigadora do Instituto de História Contemporânea da Universidade Nova de Lisboa (IHC/UNL), onde coordena o Grupo de Investigação Justiça, Regulação e Sociedade e realiza o pós-doutoramento, com apoio da Fundação para a Ciência e a Tecnologia (FCT). Doutora em História Contemporânea pela Faculdade de Ciências Sociais e Humanas da Universidade Nova de Lisboa, publicou: Igreja Católica, Estado e Sociedade (1968-1975): o caso Rádio Renascença (Imprensa de Ciências Sociais, 2005), que recebeu o Prêmio Fundação Mário Soares; A Questão Religiosa no Parlamento (1935-1974) (Assembleia da República, 2011) e A Segunda Separação. A Politica Religiosa do Estado Novo (Almedina, 2016).

- Researcher at the Instituto de História Contemporânea da Universidade Nova de Lisboa (IHC/UNL), where she coordinates the Research Group Justiça, Regulação e Sociedade. She holds a post-doctoral fellowship with the support of Fundação para a Ciência e a Tecnologia (FCT). PhD in Contemporary History from the Universidade Nova de Lisboa, she is the author of Igreja Católica, Estado e Sociedade (1968-1975): o caso Rádio Renascença (Imprensa de Ciências Sociais, 2005), which won the Prêmio Fundação Mário Soares; A Questão Religiosa no Parlamento (1935-1974) (Assembleia da República, 2011) and A Segunda Separação. A Política Religiosa do Estado Novo (Almedina, 2016). 